\title{
Application of Coupled Inductors for Reducing Switching Stresses in a Hybrid Power System
}

\author{
Dharani $\mathbf{M}^{*}$, Usha $\mathbf{P}$ \\ Department of Electrical and Electronics Engineering, Dayananda Sagar College of Engineering, \\ Bangalore, India \\ *Corresponding author, e-mail: m.dharani807@gmail.com
}

\begin{abstract}
This paper presents a novel methodology using coupled inductor for hybridizing multi input sources. A four port three input $d c-d c$ converter is chosen, two photovoltaic sources and a storage medium are interfaced with the converter. The two sources can supply the load as well as charge the battery. Four independently controlled switches are employed to provide dc regulated output. The hybridization of the sources and converter is achieved by coupled inductors. The results show that the presence of coupled inductors increases the voltage gain and reduces the switching stress. The proposed system is verified and validated in MATLAB environment under various operating condition.
\end{abstract}

Keywords: hybridization, DC-DC boost converter, coupled inductor, voltage gain, switching stress, solar cell with MPPT algorithm

Copyright $@ 2015$ Institute of Advanced Engineering and Science. All rights reserved.

\section{Introduction}

In recent decades green energy technology is acquiring a lot attention towards energy production which gives clean and residue free energy and these gives the motivation of producing power using renewable energy sources. The main constraint in using renewable source like solar is matching load requirement and extracting maximum power from it. To overcome this, multi input converter topology are investigated which integrates various renewable sources into a unique structure. Depending on the literature survey, now a days various kinds of converter topologies have been proposed due to the advantages of multiport converters configurations. One could select a proper topology by considering many aspects such as bulkiness, overall cost and reliability depending on the applications. Reference [1] presents the combination strategy on multi port converters for sharing switches, capacitors, and inductors. A high voltage gain is achieved in [2] by connecting a converter to a voltage gain extension cell such as coupled inductor, isolation transformer and switched capacitors. Reference [3] explains the significance of coupled inductor and active clamp circuits in DC-DC converters. The paper [4] has been mainly focused on the control system of multiple-input power electronic converter which has been devoted to combine the power flowing of multisource onboard energy systems. Two powerful and practical methods for maximum power point tracking of PV systems are investigated and compared in paper [5], the optimal control strategy for MPPT strongly depends on matching load and tracker characteristics. The paper [6] presents a new FC-battery hybrid power system analysis and design, where active current sharing and source management is achieved. A three-port series resonant converter was introduced in [7] to interface renewable energy sources and the load, along with energy storage. It was proven by analysis and experimental results that power flow between ports can be controlled by series resonance and phase-shifting the square wave outputs of the three ports. The proposed converter in [8] is supplied by different DG sources such as a PV array, a Fuel cell and a Battery. This structure provides accurate MPPT of PV array, FC optimal power operation and battery charging/discharging performances simultaneously. Paper [9] proposes the MPPT technique for tracking maximum power from the solar using single stage MPPT controller. Reference [10] gives the combinational result of solar-battery system whose proper control mechanism controls the output through outer loop and renewable source by inner loop. Reference [11] presents a concept on multiple dc sources connected in a unique manner in 
which the small inductor reduces the converter power losses and thereby reducing the size of the parasitic capacitor. The four port converter topology for hybrid system [12-14] explains the controlling technique of multiple sources supplying individually the load under various operating conditions during different duty ratios. Modeling and simulation for switching mode DC-DC power supplies with soft switching nature for improving the efficiency of solar energy systems are given under [15-16]. Reference [17] gives the controlling technique for four port bidirectional DC-DC converter for PV/ battery systems. Seeing to the overall idea on these concepts a newly proposed DC-DC converter is presented in this paper. Figure 1 gives the overall topology of using multi inputs in a hybridized manner whose controlling strategy depends on the input sources which is regulated by duty ratio of the switches.

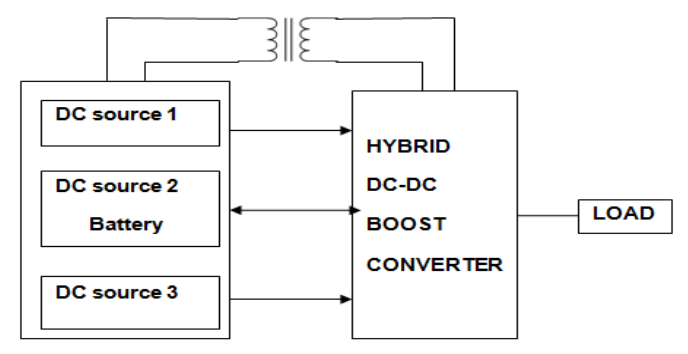

Figure 1. Block Diagram of High Voltage Gain Multi-input DC-DC Converter

The organization of the paper is as follows: the operating principal of the converter are discussed under section II. The operating modes of the converter are discussed in section III. The performance wise results are simulated and validating results are explained in section IV and future development and scope on this area is discussed under V.

\section{Principal of Operation}

This section deals with the basic principal under which the high voltage gain multi input DC-DC boost converter work. It basically consists of three dc sources which are integrated in a unique manner to achieve maximum reliability. One of such sources is a bi-directional battery which has charging/discharging capability. The other two sources are solar cells which gives variable dc source. The output voltage is regulated under various operating conditions depending on the duty ratio of the switches. It consists of four MOSFET switches operating under different instant to control the performance of the converter topology. Two solar panels at its extreme operating range under high irradiance level is capable of satisfying the load demand. If there is any decrease in the input source range the decreased level is compensated by the use battery which is discussed in detail in three different operating modes. A coupled inductor is used in between the source block and converter block creating a isolation between them and reducing the switching stress across switches and producing high gain comparatively. Inductors L1 and L2 are source inductance of dependent sources. The converter operation is also operated under soft switching nature to avoid switching losses.

\section{Operating Modes of the Converter}

The proposed multi-input dc-dc hybrid boost converter topology integrating two PV cells and a battery is as shown in the Figure 2.

The converter structure interfaces two input power sources V1 and V2. Where V1 and V2 are taken as renewable energy sources normally solar panels are employed in this structure. Since solar panel output depends on the nominal weather condition and irradiation level of sun, battery is used as the storage elements for supplying load during low intensity level of solar energy. Four MOSFET switches are used in the circuit for allowing hybridization between the sources. Since four switches are employed in the circuit the voltage stress on the switches is found to be high. To overcome this inconsistency coupled inductor is incorporated into the

TELKOMNIKA Vol. 16, No. 3, December 2015: $463-472$ 
circuit between the two sources and a boosting action is performed. The duty ratio lies in the range of 0.6-0.7 for different operating modes of converter.

Operating modes of the converter maintained at $20 \mathrm{kHz}$ switching frequency and at specified duty ratio are:

1) No battery contribution mode.

2) Battery discharging mode.

3) Battery charging mode.

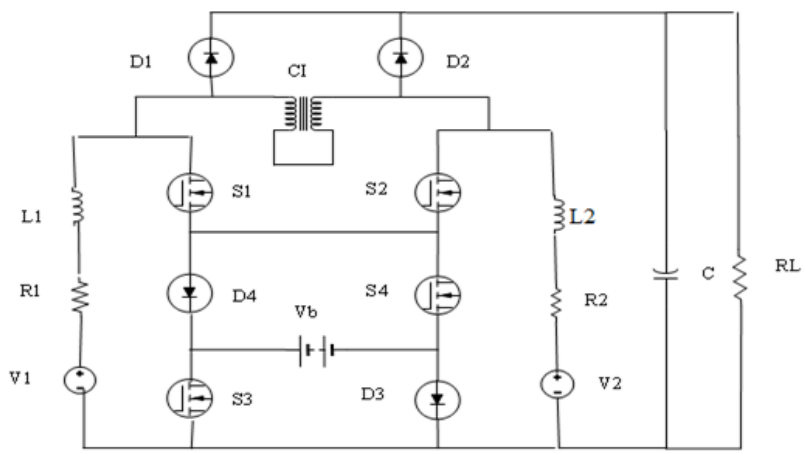

Figure 2. Circuit topology of the proposed system

The choice of selecting the mode of operation depends on the state of input requirements; control logic is defined for this particular case using duty ratio adjustment. The algorithm which states the choice of mode selection is as given in the Figure 3 .

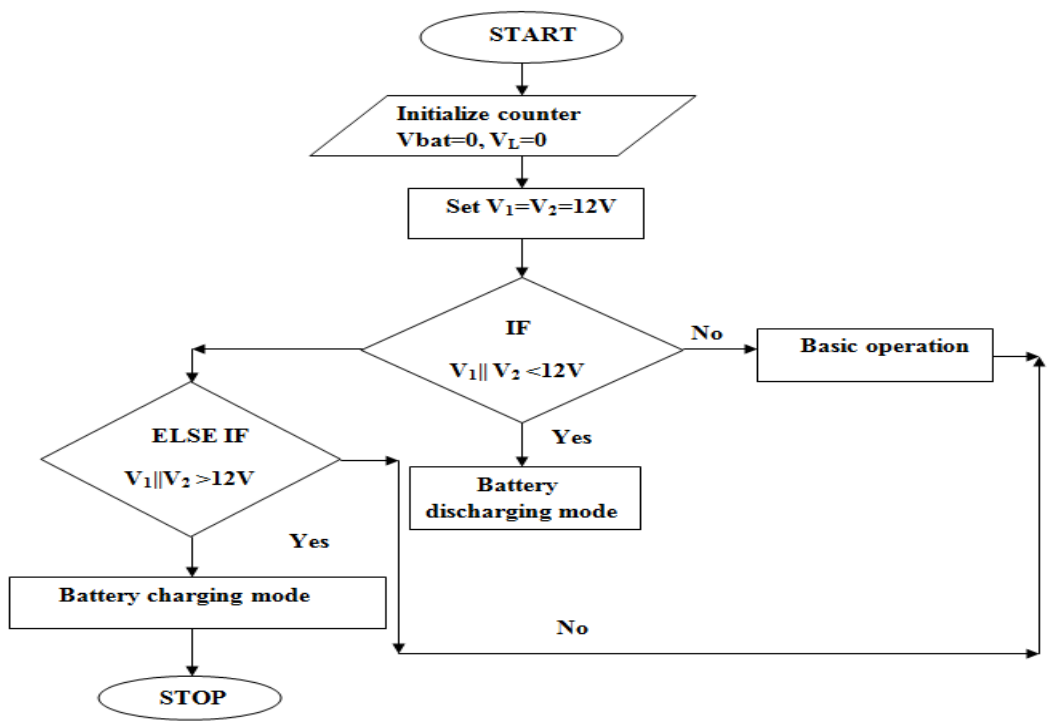

Figure 3. Switching algorithm of operating modes

\subsection{First Operating Mode}

In this operating mode, two input power sources V1 and V2 are supplying the load and battery has no existence during this mode. This operating mode is said to be a basic operating mode of the converter. This is achieved under maximum irradiance level. Three different switching states are obtained under this operating mode. The switching pattern for this mode is as depicted in the Table1. 
Table 1. Switching States of mode 1

\begin{tabular}{cccccc}
\hline Switching State & Duty Cycle & S1 & S2 & S3 & S4 \\
\hline State 1 & $0<\mathrm{t}<\mathrm{d}_{1} T$ & OFF & ON & ON & OFF \\
State 2 & $d_{1} T<t<d_{2} T$ & ON & OFF & OFF & ON \\
State 3 & $d_{2} T<t<T$ & OFF & OFF & OFF & OFF \\
\hline
\end{tabular}

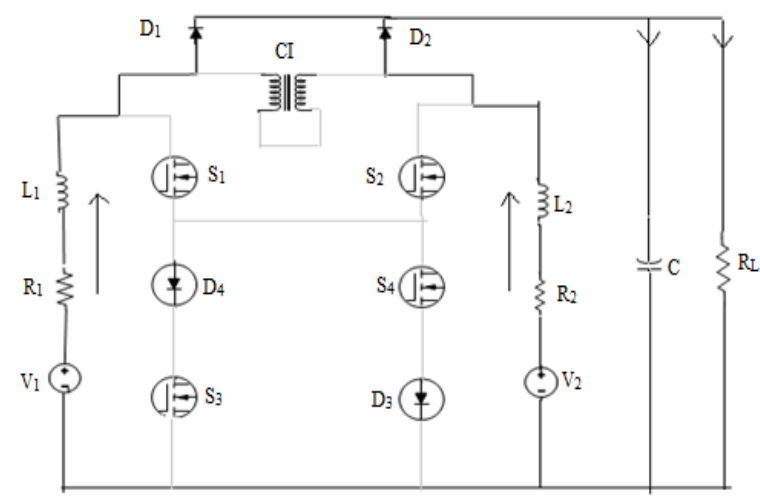

Figure 4. First operating mode

Applying voltage balance law to this mode, the following expressions are obtained:

$$
\begin{aligned}
& L_{1}: d_{2} T\left(V_{1}-i_{L 1} \cdot r_{1}\right)+d_{3} T\left(V_{1}-r_{1} \cdot i_{L 1}\right)+M\left(V_{1}-V_{2}\right) \\
& L_{2}: d_{1} T\left(V_{2}-i_{L 2} \cdot r_{2}\right)+d_{4} T\left(V_{2}-r_{2} \cdot i_{L 2}\right)+M\left(V_{1}-V_{2}\right) \\
& C:\left(1-d_{1}\right) T_{L 1}+\left(1-d_{2}\right) T i_{L 2} \\
& I_{\text {batt }}=0, P_{\text {batt }}=0
\end{aligned}
$$

It is observed that the battery current and battery power are zero, which justifies that no power is delivered from the battery and proves that load is satisfied only by the two voltage sources V1 and V2.

\subsection{Second Mode of Operation}

In this operating mode we can observe three input sources operated to satisfy the load demand under appropriate switching condition. Under this mode we have four different switching states and since there is a existence of battery which is going to discharge in this mode. This mode of operation is said to be battery discharging mode. This mode comes into existence during any power decrease in V1 and V2. The decreased amount of power from the solar sources is supplied by the battery and satisfies the load demand maintaining the regulated output voltage constant.

Table 2. Switching States of mode 2

\begin{tabular}{llllll}
\hline Switching State & Duty Cycle & S1 & S2 & S3 & S4 \\
\hline State 1 & $0<\mathrm{t}<\mathrm{d}_{4} \mathrm{~T}$ & ON & OFF & ON & ON \\
State 2 & $\mathrm{~d}_{4} \mathrm{~T}<\mathrm{t}<\mathrm{d}_{1} \mathrm{~T}$ & OFF & ON & ON & OFF \\
State 3 & $\mathrm{d}_{1} \mathrm{~T}<\mathrm{t}<\mathrm{d}_{2} \mathrm{~T}$ & ON & OFF & OFF & ON \\
State 4 & $\mathrm{~d}_{2} \mathrm{~T}<\mathrm{t}<\mathrm{T}$ & OFF & OFF & OFF & OFF \\
\hline
\end{tabular}

TELKOMNIKA Vol. 16, No. 3, December 2015 : $463-472$ 


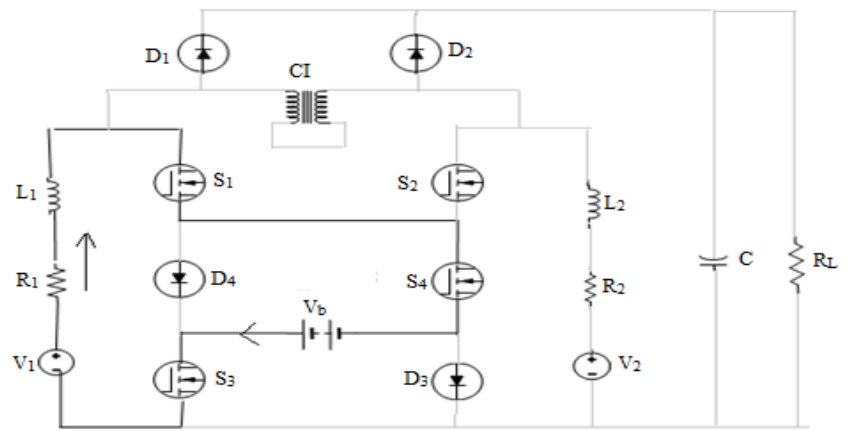

Figure 5. Second operating mode

Applying voltage balance law to this mode, the following expressions are obtained:

$$
\begin{aligned}
& \mathrm{L}_{1}: \mathrm{d}_{4} \mathrm{~T}\left(\mathrm{~V}_{1}-\mathrm{i}_{\mathrm{L} 1} \cdot \mathrm{r}_{1}+\mathrm{V}_{\mathrm{b}}\right)+\left(1-\mathrm{d}_{1}\right) \mathrm{T}\left(\mathrm{V}_{1}-\mathrm{r}_{1} \cdot \mathrm{i}_{\mathrm{L} 1}-\mathrm{V}_{0}\right)+\left(\mathrm{d}_{1}-\mathrm{d}_{4}\right) \mathrm{T}\left(\mathrm{V}_{1}-\mathrm{r}_{1} \cdot \mathrm{i}_{\mathrm{L} 1}\right) \\
& +M\left(V_{1}-V_{2}\right) \\
& \mathrm{L}_{2}: \mathrm{d}_{4} \mathrm{~T}\left(\mathrm{~V}_{2}-\mathrm{i}_{\mathrm{L} 2} \cdot \mathrm{r}_{2}+\mathrm{V}_{\mathrm{b}}\right)+\left(1-\mathrm{d}_{2}\right) \mathrm{T}\left(\mathrm{V}_{2}-\mathrm{r}_{2} \cdot \mathrm{i}_{\mathrm{L} 2}-\mathrm{V}_{0}\right)+\left(\mathrm{d}_{2}-\mathrm{d}_{4}\right) \mathrm{T}\left(\mathrm{V}_{2}-\mathrm{r}_{2} \cdot \mathrm{i}_{\mathrm{L} 2}\right) \\
& +\mathrm{M}\left(\mathrm{V}_{1}-\mathrm{V}_{2}\right) \\
& C:\left(1-d_{1}\right) \mathrm{Ti}_{\mathrm{L} 1}+\left(1-\mathrm{d}_{2}\right) \mathrm{Ti}_{\mathrm{L} 2} \\
& \text { Battery discharging } \mathrm{i}_{\text {batt }}=\mathrm{d}_{4}\left(\mathrm{iL}_{1}+\mathrm{iL}_{2}\right) \\
& \mathrm{P}_{\text {batt }}=\mathrm{V}_{\mathrm{b}}\left(\mathrm{d}_{4}\left(\mathrm{iL}_{1}+\mathrm{iL}_{2}\right)\right)
\end{aligned}
$$

The first state in this mode is battery discharging state which combines with the source V1 to produce as the single source, the decrease in power of V1 is now in series with battery power to produce the set range, the other three states depicts the same operation as basic mode.

\subsection{Third Mode of Operation}

This mode of operation is explained for cases when renewable energy sources are used at its peak range and battery backup is provided under off peak periods. In off peak periods the power decrease is compensated by external energy storage devices to meet the load demand and in peak periods these energy storage devices such as battery is being charged for further use. This mode of operation is explained for peak period of renewable sources and has four operating states during which the battery is getting charged and hence it is said to be charging mode.

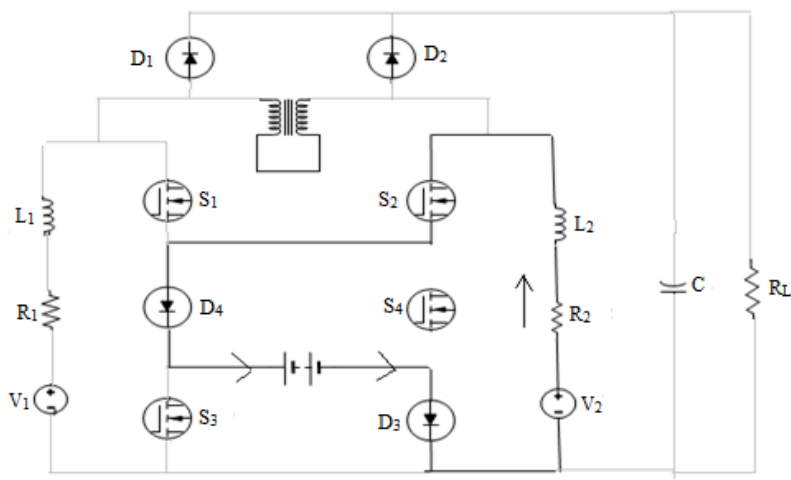

Figure 6. Third Operating Mode 
Table 3.Switching States of mode 3

\begin{tabular}{llllll}
\hline Switching State & Duty Cycle & S1 & S2 & S3 & S4 \\
\hline State 1 & $0<\mathrm{t}<\mathrm{d}_{4} \mathrm{~T}$ & OFF & ON & OFF & OFF \\
State 2 & $\mathrm{d}_{4} \mathrm{~T}<\mathrm{t}<\mathrm{d}_{1} \mathrm{~T}$ & OFF & ON & ON & OFF \\
State 3 & $\mathrm{d}_{1} \mathrm{~T}<\mathrm{t}<\mathrm{d}_{2} \mathrm{~T}$ & ON & OFF & OFF & ON \\
State 4 & $\mathrm{d}_{2} \mathrm{~T}<\mathrm{t}<\mathrm{T}$ & OFF & OFF & OFF & OFF
\end{tabular}

$$
\begin{aligned}
& P_{\max }(\text { battery Charging })=-\mathrm{V}_{\mathrm{b}}\left(\mathrm{d}_{1} \cdot \mathrm{iL}_{1}+\mathrm{d}_{2} \cdot \mathrm{iL}_{2}\right) \\
& \mathrm{L}_{1}: \mathrm{d}_{3} \mathrm{~T}\left(\mathrm{~V}_{1}-\mathrm{i}_{\mathrm{L} 1} \cdot \mathrm{r}_{1}\right)+\left(1-\mathrm{d}_{1}\right) \mathrm{T}\left(\mathrm{V}_{1}-\mathrm{r}_{1} \cdot \mathrm{i}_{\mathrm{L} 1}-\mathrm{V}_{0}\right)+\left(\mathrm{d}_{1}-\mathrm{d}_{3}\right) \mathrm{T}\left(\mathrm{V}_{1}-\mathrm{r}_{1} \cdot \mathrm{i}_{\mathrm{L} 1}-\mathrm{V}_{\mathrm{b}}\right) \\
& +\mathrm{M}\left(\mathrm{V}_{1}-\mathrm{V}_{2}\right) \\
& \mathrm{L}_{2}: \mathrm{d}_{2} \mathrm{~T}\left(\mathrm{~V}_{2}-\mathrm{i}_{\mathrm{L} 2} \cdot \mathrm{r}_{2}\right)+\left(1-\mathrm{d}_{2}\right) \mathrm{T}\left(\mathrm{V}_{2}-\mathrm{r}_{2} \cdot \mathrm{i}_{\mathrm{L} 2}-\mathrm{V}_{0}\right)+\left(\mathrm{d}_{2}-\mathrm{d}_{3}\right) \mathrm{T}\left(\mathrm{V}_{2}-\mathrm{r}_{2} \cdot \mathrm{i}_{\mathrm{L} 2}-\mathrm{V}_{\mathrm{b}}\right) \\
& +\mathrm{M}\left(\mathrm{V}_{1}-\mathrm{V}_{2}\right) \\
& C:\left(1-\mathrm{d}_{1}\right) \mathrm{Ti}_{\mathrm{L} 1}+\left(1-\mathrm{d}_{2}\right) \mathrm{Ti}_{\mathrm{L} 2} \\
& \mathrm{I}_{\text {batt }}=-\left(\mathrm{d}_{1}-\mathrm{d}_{3}\right) \mathrm{iL}_{1}-\left(\mathrm{d}_{2}-\mathrm{d}_{3}\right) \mathrm{iL}_{2} \\
& P_{\text {batt }}=V_{b}\left[-\left(d_{1}-d_{3}\right) i_{1}-\left(d_{2}-d_{3}\right) i_{2}\right]
\end{aligned}
$$

During this mode the source V1 and V2 supplies both battery and load which makes the regulated output DC voltage to remain constant.

\section{Simulation Results}

The proposed converter topology is been validated in MATLAB environment. The behavior of the converter in all the three modes are simulated and the results are been tabulated. The regulated dc output is found to be $110 \mathrm{v}$ and $30 \mathrm{w}$ power. A lamping load of $6 \mathrm{w}$ is chosen and the performance is analyzed. Two PV cells are modeled with maximum power of 30w and the behavior of it under MPPT condition is as given in the Figure 7 and 8 . The maximum power is extracted using perturb and observe method under $1000 \mathrm{w} / \mathrm{m}^{2}$ irradiation.

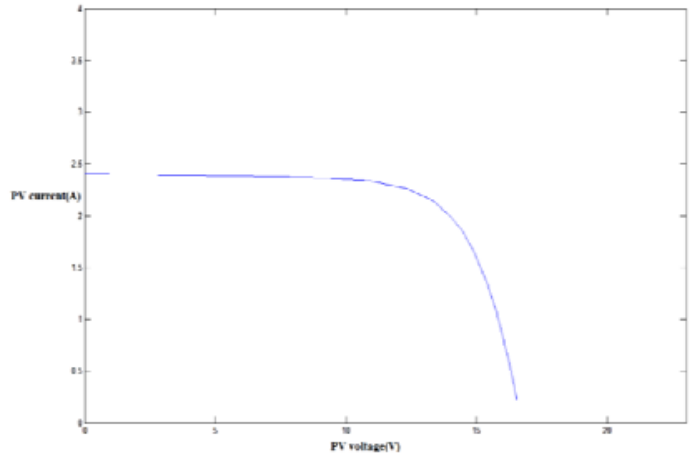

Figure 7. P-V Characteristics of Solar Panel

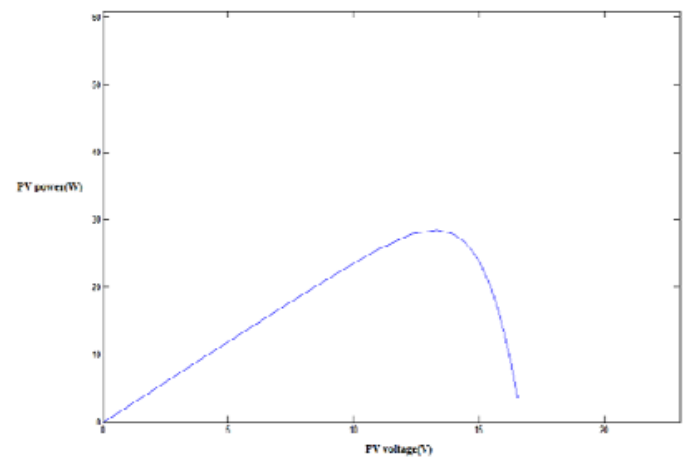

Figure 8. I-V Characteristics of Solar Panel

It is seen that the maximum power extracted from the solar cell using MPPT algorithm is $30 \mathrm{w}$ for nominal operating voltage $17 \mathrm{v}$, the corresponding $\mathrm{P}-\mathrm{V}$ and I-V curves are as shown in the Figure 7 and 8.using this solar cells as the two input sources and battery, the converter is simulated in MATLAB. All the three modes of the converter results are seen with its corresponding duty ratio. Depending on the simulation results three modes are discussed.

First simulation stage: During this stage the converter is operated only under two renewable sources. this comes into existence during peak irradiation levels where there is no need for additional power to be supplied to satisfy the load demand, and this is said to be the 
basic set up of the converter. The output of the DC-DC converter is same in all the three stages and input power remains constant under various circumstances.

Second simulation stage: This stage of the converter is said to be battery discharging stage since the input power decrease due to various weather change can be compensated using the additional energy storage medium. The battery voltage comes in series with the corresponding source delivering voltage less than the pre set voltage. The duty ratio under which this mode is operated is as shown in the Figure 9.

Third simulation stage: This stage of the converter is chosen during optimum range input from both the solar cells and capable of satisfying both load demand and charging the battery. During this stage battery also behaves as load and the charging current across battery during this mode of operation is as shown in the Figure 17.

The switching patterns of all the three stages are discussed individually. The generalized switching pattern is as shown in the Figure 8 which allow all the three sources to supply the load requirement.

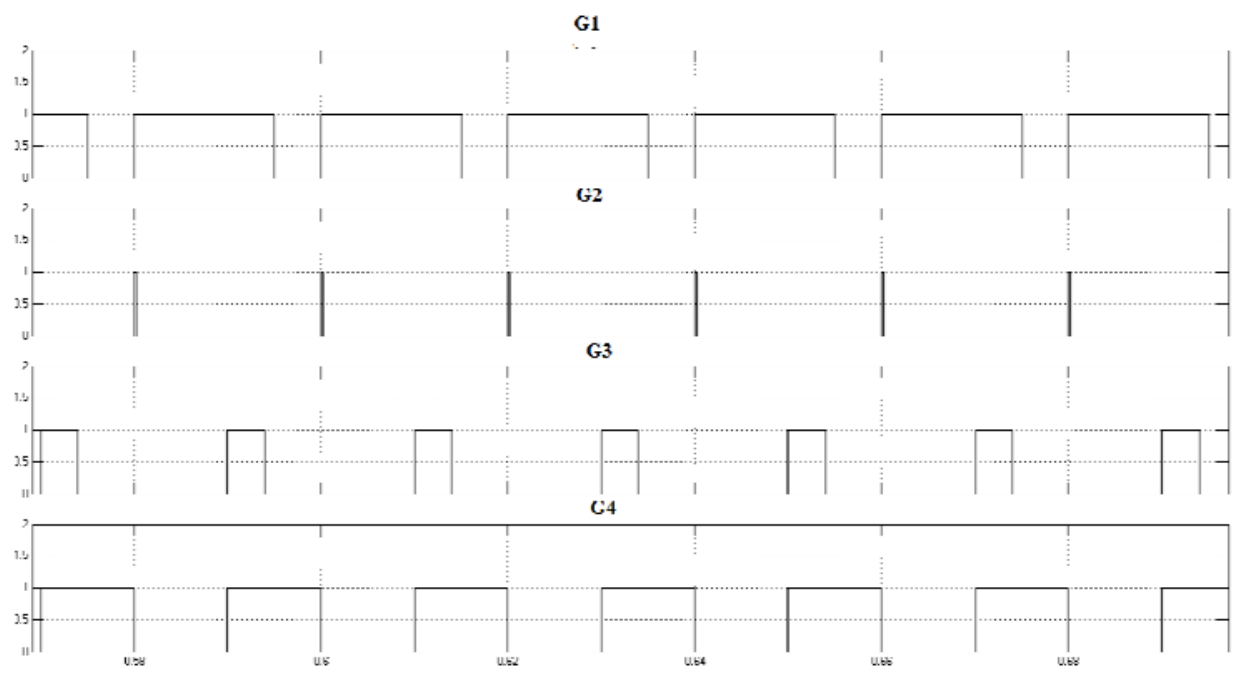

Figure 9. Switching Pattern

The regulated DC output voltage and current under all three operating modes is as shown in the Figure 10 and Figure 11.

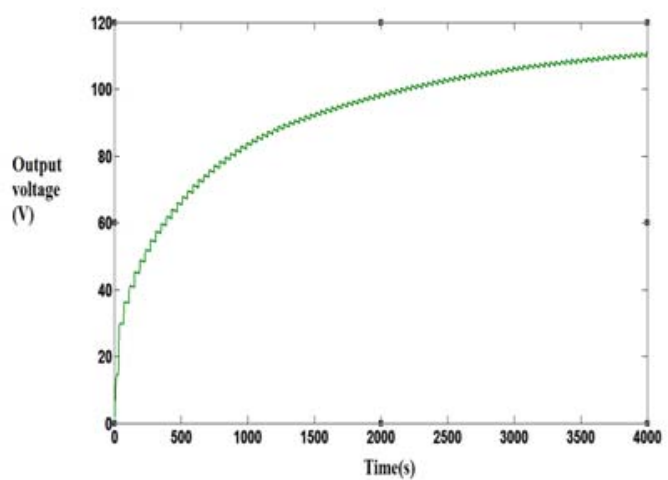

Figure 10. Output Voltage Waveform

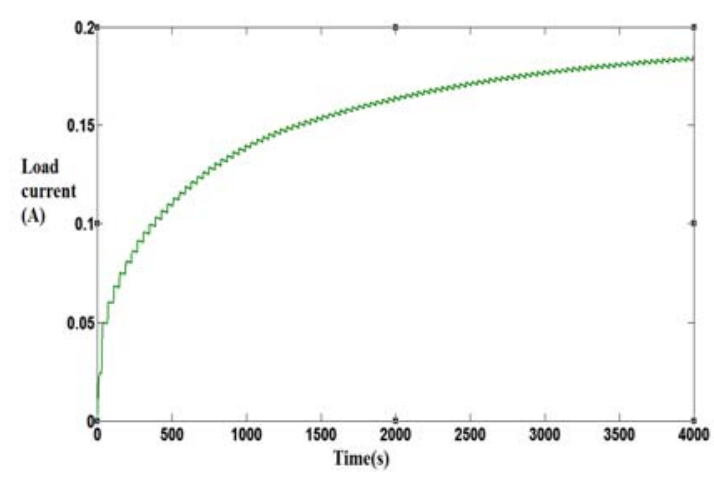

Figure 11. Output Current Waveform

The presence of coupled inductor allows in less switching stress and soft switching behavior of the switches is also seen as in the Figure12 and Figure 13. 
The soft switching nature allows the switches to operate under either current zero or voltage zero to reduce power loss across the switches which contribute to overall converter losses and thereby increasing the overall converter efficiency. The stress across switches for $110 \mathrm{v} d c$ output is found to be in the range of 5-10v for all the four switches.

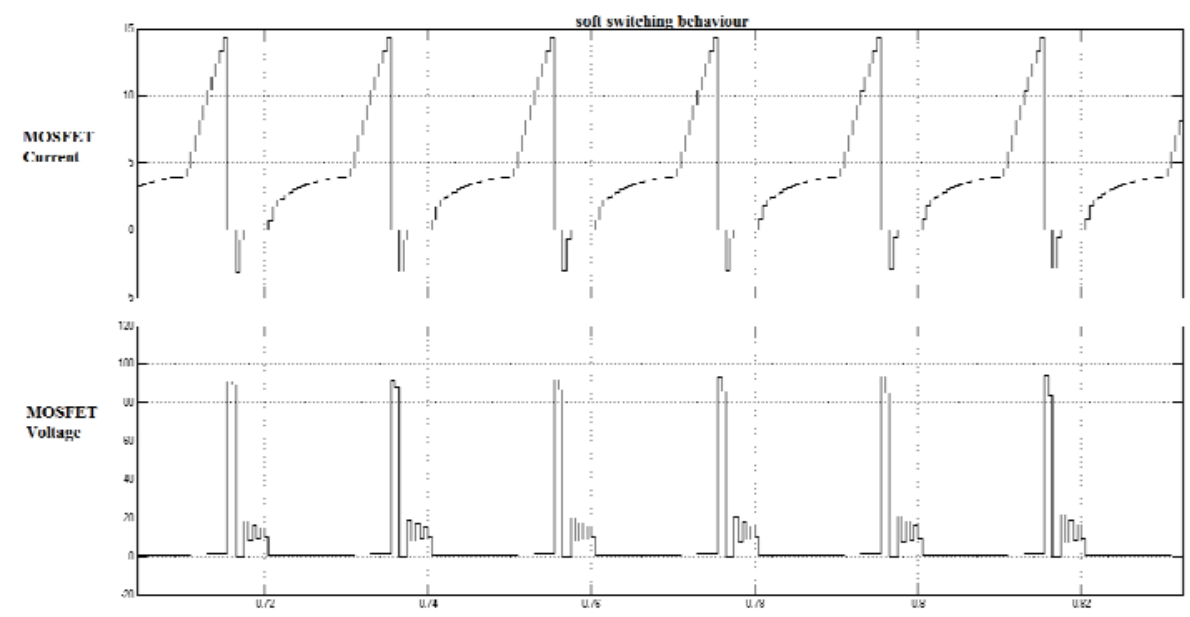

Figure 12. Soft Switching Behavior Of MOSFET Switches

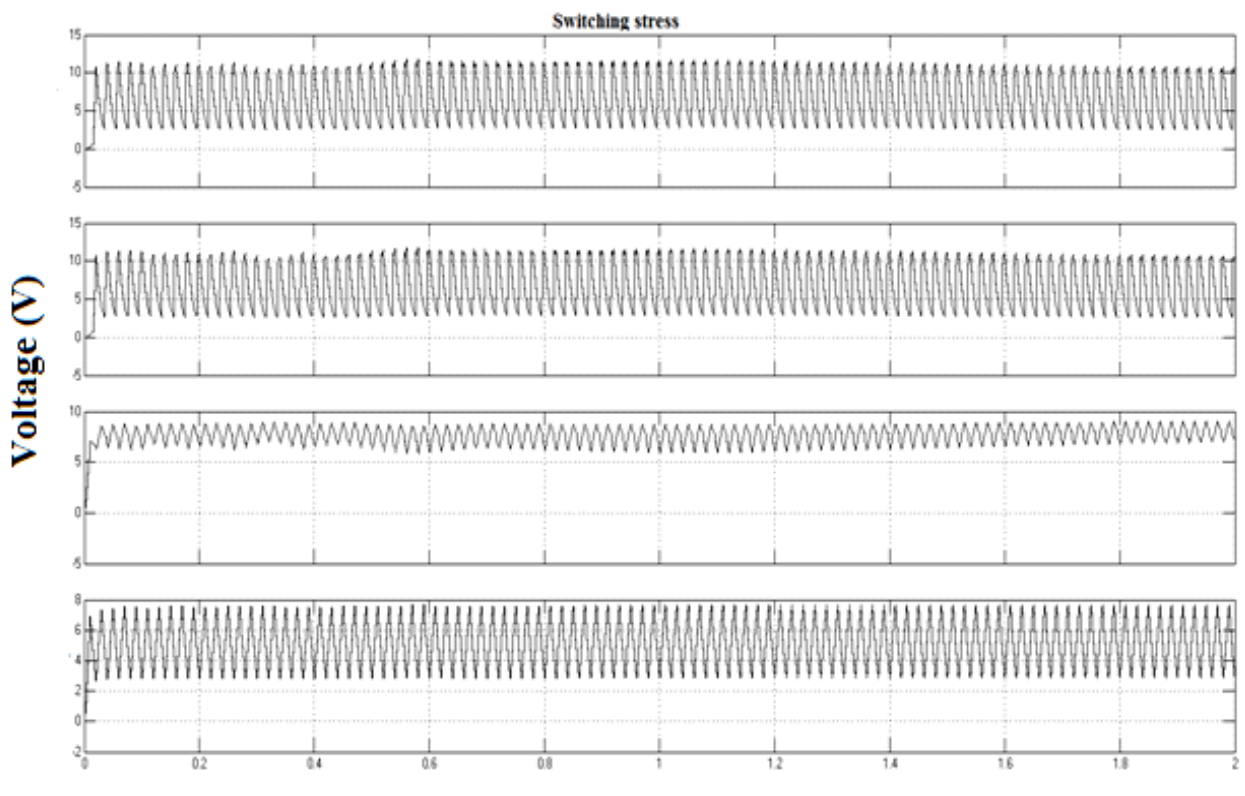

Time (s)

Figure 13. Switching Stress Across MOSFET Switches

The current across source inductance for dependent sources for all the three modes is as shown in the Figure14.

TELKOMNIKA Vol. 16, No. 3, December 2015 : $463-472$ 


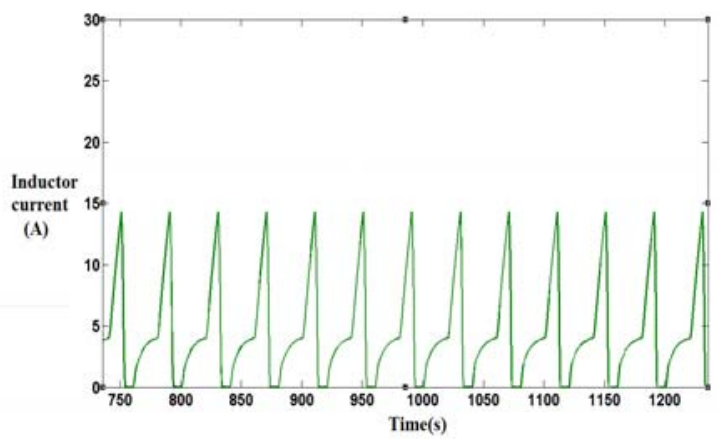

Figure 14. Inductor Current

The battery of capacity $6 \mathrm{v}$ and $4.5 \mathrm{Ah}$ is applied, the discharging capacity of the battery during discharging mode of operation is as shown in the Figure 16.

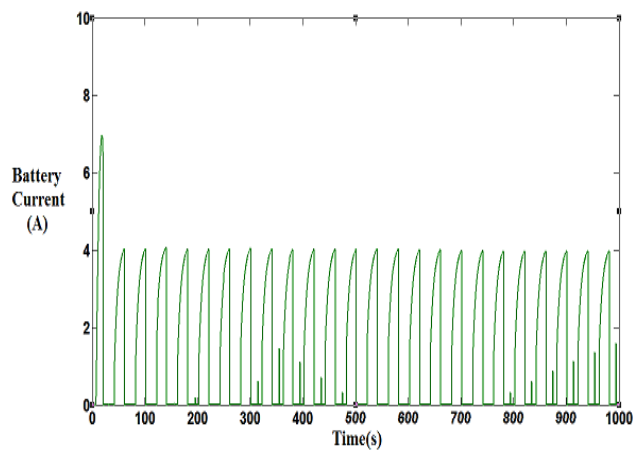

Figure 15. Battery current

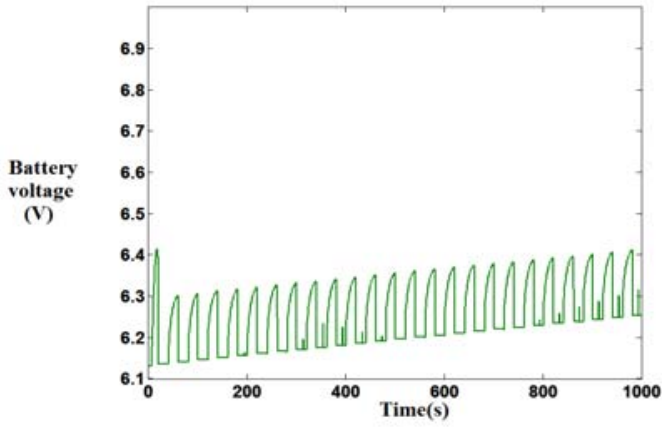

Figure 16. Battery voltage

The performance of the battery during charging mode i.e the battery current during charging mode is as shown in the Figure 15.

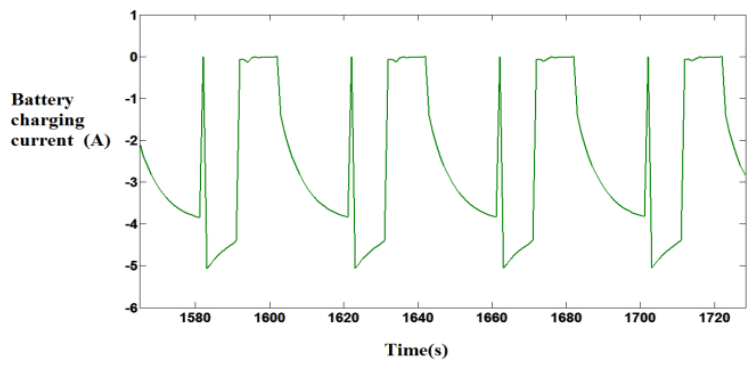

Figure 17. Battery charging current

\section{Conclusion}

A hybrid boost DC-DC converter with less switching stress and soft switching behavior for solar applications is proposed in this paper. The power flow across the load is regulated using duty ratio of the switches, depending on the utilization state of battery three modes of operation are defined and the results are tabulated. The converter mode equations are found using voltage balance law and the results are seen in the MATLAB environment. Stress 
reduction achieves in higher voltage gain and lesser converter losses which are validated in the results therefore the overall efficiency of the converter is increased. The implemented methodology is a better suit for producing higher voltages from solar energy sources with simple design and lower cost. This can also be implemented on other alternative energy sources for the effective use of pollution free energy production.

\section{References}

[1] SH Choung, A Kwasinski. Multiple-input DC-DC converter topologies comparison. In Proc. 34th Annu. Conf. IEEE Ind. Electron. 2008: 2359-2364.

[2] A Huang. A vision for the future grid, In Proc. IEEE Power Energy Soc. Gen. Meet. 2010: 1-4

[3] W Li, X He. Review of non isolated high-step-up DC/DC converters in photovoltaic grid-connected applications. IEEE Trans. Ind. Electron. 2011; 58(4): 1239-1250.

[4] JL Duarte, M Hendrix, MG Simoes. Three-port bidirectional converter for hybrid fuel cell systems. IEEE Trans. Power Electron. 2007; 22(2): 480-487.

[5] N Kato, K Kurozumi, N Susuld, S Muroyama. Hybrid power supply system composed of photovoltaic and fuel-cell systems. In Proc. Int. Telecommun. Energy Conf. 2001: 631-635.

[6] OC Onara, M Uzunoglu, MS Alam. Modeling, control and simulation of an autonomous wind turbine/photovoltaic/fuel cell/ultra capacitor hybrid power system. J. Power Sources. 2008; 185(2): 1273-1283.

[7] R Gopinath, S Kim, JH Hahn, PN Enjeti, MB Yeary, JW Howze. Development of a low cost fuel cell inverter system with DSP control. IEEE Trans. Power Electron. 2004; 19(5): 1256-1262.

[8] Wide Input Range DC to DC Converter. Design Note DN06007/D. ON Semiconductor. www.onsemi.com.

[9] Wuhua Li, Xiangning He. Review of high step DC-DC converter in photovoltaic grid connected application. IEEE Trans. on Industrial Electronics. 2011; 58(4).

[10] Miaosen Shen, Fang Zheng Peng and Leon M. Tolbert. Multilevel DC-DC Power Conversion System With Multiple DC Sources. IEEE TRANSACTIONS ON POWER ELECTRONICS. 2008; 23(1).

[11] Tsai-Fu Wu, jeng-Gung Yang. Soft-switching bi-directional isolated full-bridge converter with active and passive snubbers. IEEE Trans. on Industrial Electronics. 2014; 61(3).

[12] Ben York, Wensong Yu, Jih-Sheng. An Integrated Boost Resonant Converter for Photovoltaic Applications. IEEE TRANSACTIONS ON POWER ELECTRONICS. 2013; 28(3).

[13] Farzam Nejabatkhah, Saeed Danyali, Seyed Hossein Hosseini, Mehran Sabahi. Modeling and Control of a New Three-Input DC-DC Boost Converter for Hybrid PV/FC/Battery Power System. IEEE TRANSACTIONS ON POWER ELECTRONICS. 2012; 27(5).

[14] Yang Han. A Pedagogical Approach for Modeling and Simulation of Switching Mode DC-DC Converters for Power Electronics Course. TELKOMNIKA Indonesian Journal of Electrical Engineering. 2012; 10(6): 1319-1326.

[15] Alireza Kaviani-Arani, Alireza Gheiratmand. Soft Switching Boost Converter Solution for Increase the Efficiency of Solar Energy Systems. TELKOMNIKA Indonesian Journal of Electrical Engineering. 2015 13(3): 449-457.

[16] Shangguan, Xuanfeng, Huimin Yang, Yongliang Wang, Benlong Shi. The Design and Simulation of Improved and Multiplex Boost Converter. TELKOMNIKA Indonesian Journal of Electrical Engineering. 2014; 12(4): 2599-2605.

[17] Dharani. M, P Usha. A Novel Topology for Controlling a Four Port DC-DC Boost Converter for a Hybrid PV/PV/Battery Power System. TELKOMNIKA Indonesian Journal of Electrical Engineering. 2015; 14(3): 446-454.

TELKOMNIKA Vol. 16, No. 3, December $2015: 463-472$ 